\title{
MONITORING THE EFFECTIVENESS OF WEED CONTROL
}

\author{
A.I. POPAY \\ Deptartment of Conservation, PO Box 112, Hamilton \\ Corresponding author: ipopay@doc.govt.nz
}

Several government agencies in New Zealand carry out weed control programmes. The Department of Conservation (DOC) spends nearly $\$ 10$ million a year on weed control. The aim is to protect biodiversity, but do we know we're winning and can we prove it? Answering those questions calls for independent monitoring of progress. DOC developed standard operating procedures to help staff scientifically measure progress of weed control programmes, and aims to monitor one third of its programmes. Most of DOC's monitoring measures result - how well the target weed is controlled. For some projects the conservation outcome of the control is monitored - whether native biodiversity has increased or the plight of threatened species improved. For outcome monitoring, weed plots remain untreated as an experimental control, so we can be sure that weed control led to the outcome, rather than other factors. Monitoring is an integral part of weed control and must comply with scientific standards to be useful. It is too early to say whether DOC's monitoring activity is improving weed control operations and affecting conservation outcomes. We are confident that monitoring procedures are rigorous and deliver meaningful results. Other agencies like Regional Councils are welcome to use our methods.

\section{HOW WEEDY ARE PLANTS RECENTLY NATURALISED IN NEW ZEALAND?}

\author{
P.A. WILLIAMS ${ }^{1}$ and R. RANDALL ${ }^{2}$ \\ ${ }^{1}$ Landcare Research, Private Bag 6, Nelson, New Zealand \\ ${ }^{2}$ Department of Agriculture, Locked bag 4, Bently DC 6983, Western Australia \\ Corresponding author: williamsp@landcare.cri.nz
}

Escaping from cultivation and naturalising is a critical step for all invasive plant species. The cost-effective way of preventing invasions would be to manage the naturalisation pathway and estimate the weediness of the newly naturalised species as a guide to control priorities. Since 1988 there have been 187 casual naturalisations and 79 full naturalisations reported in New Zealand (other than monocotyledons). Most (96\%) were introduced for horticulture. The majority $(64 \%)$ have naturalised elsewhere. Half $(52 \%)$ are listed as weeds overseas with an average of 8 lists per species. Many are from regions with comparable climates to New Zealand. The majority (60\%) of naturalisations are available through nurseries with an average of 6 outlets nationwide. Those listed as weeds elsewhere are sold more frequently $(60 \%)$ than those that are not weeds elsewhere $(40 \%)$. Nurseries are the main pathway in the naturalisation of invasive plants in New Zealand. This should be recognised in biosecurity legislation and action, and public education. 